\title{
Cattle remain immunocompetent during the acute phase of foot-and-mouth disease virus infection
}

\author{
Miriam A Windsor ${ }^{1}$, B Veronica Carr², Bartomiej Bankowski ${ }^{1}$, Debi Gibson', Elizabeth Reid', Pip Hamblin 1 , \\ Simon Gubbins ${ }^{1}$, Nicholas Juleff ${ }^{1}$ and Bryan Charleston ${ }^{1,2^{*}}$
}

\begin{abstract}
Infection of cattle with foot-and-mouth disease virus (FMDV) results in the development of long-term protective antibody responses. In contrast, inactivated antigen vaccines fail to induce long-term protective immunity. Differences between susceptible species have also been observed during infection with FMDV, with cattle often developing persistent infections whilst pigs develop more severe symptoms and excrete higher levels of virus. This study examined the early immune response to FMDV in naïve cattle after in-contact challenge. Cattle exposed to FMDV were found to be viraemic and produced neutralising antibody, consistent with previous reports. In contrast to previous studies in pigs these cattle did not develop leucopenia, and the proliferative responses of peripheral blood mononuclear cells to either mitogen or third party antigen were not suppressed. Low levels of type 1 interferon and IL-10 were detected in the circulation. Taken together, these results suggest that there was no generalised immunosuppression during the acute phase of FMDV infection in cattle.
\end{abstract}

\section{Introduction}

Foot-and-mouth disease (FMD) is an extremely contagious and economically important disease of livestock. Outbreaks in normally disease-free countries, such as the UK in 2001 [1] and Japan in 2010 [2], have cost billions of dollars in lost revenue. The current vaccines available for use in endemic countries do not confer long-lasting immunity and highly purified vaccine antigen is required to distinguish between vaccinated and infected animals. Understanding the complex relationship between virus and host is vital in designing new vaccines that can be targeted to those areas of the immune system most likely to induce an effective response.

The causative agent, foot-and-mouth disease virus (FMDV), spreads rapidly between animals and is quickly disseminated within the host, presumably in order to avoid the adaptive immune response (for an overview see Golde et al. [3]).

\footnotetext{
* Correspondence: bryan.charleston@iah.ac.uk

${ }^{1}$ Pirbright Laboratory, Institute for Animal Health, Ash Road, Woking, Surrey, GU24 ONF, UK

Full list of author information is available at the end of the article
}

In cattle, the primary sites of infection in aerosol transmission are the nasopharangeal tissues [4], and associated epithelial tissues [5]. Whilst several studies have examined the host response to FMDV in swine [6-10], little is known about the innate or adaptive response to FMDV in cattle. Type 1 (alpha and beta) interferons (IFN) are induced early in the innate immune response and are considered a dominant factor in shaping both innate and adaptive immune responses [11]. Type 1 IFN certainly seems to play a role in FMD pathogenesis in swine, and Chinsamgaram et al. propose that during infection, type 1 IFN production is regulated by the leader protein of FMDV $\left(\mathrm{L}^{\mathrm{pro}}\right)$ [12]. However, prophylactic administration of IFN by adenovirus vector prior to challenge, rapidly induces a protective state in swine [13]. Two studies in swine used direct inoculation of FMDV challenge methods to identify a period of lymphopenia approximately 2 to 4 days post challenge that coincided with peak viraemia $[7,14]$. In addition, in both studies the animals showed suppression of $\mathrm{T}$ cell proliferation in response to mitogen from day 1 to day 7 [14] and day 2 to day 5 or 8 depending on the virus used [7]. Lymphopenia had also been correlated with loss of plasmacytoid dendritic cell (PDC)
Ciomed Central

() 2011 Windsor et al; licensee BioMed Central Ltd. This is an Open Access article distributed under the terms of the Creative Commons Attribution License (http://creativecommons.org/licenses/by/2.0), which permits unrestricted use, distribution, and reproduction in any medium, provided the original work is properly cited. 
function and inhibition of $\mathrm{T}$ cell function [10]. A study in cattle and Indian buffalo has provided limited evidence of a transient lymphopenia immediately after infection [15]. In swine this immune suppression has also been linked with elevated levels of IL-10 in serum [10]. IL-10 is widely acknowledged to contribute to the anti-inflammatory response and to the inhibition of cellular responses via a variety of mechanisms (for a review see [16]). There is also evidence that natural killer (NK) cells may be functionally defective during infection [17].

In cattle, cytotoxic $\mathrm{T}$ lymphocytes (CTL) have been shown to play a role in the FMDV immune response during infection and vaccination $[18,19]$ in a cross serotypic manner [20]. Studies carried out on the proliferative response of cattle peripheral blood lymphocytes following vaccination showed a heterotypic reaction, indicating a sharing of $\mathrm{T}$ cell epitopes [21]. When Garcia-Valcarcel et al. inoculated an animal with FMDV, little proliferation was seen until a subsequent re-challenge, when a cross serotype response was observed [22].

The humoral response to FMDV is well documented, with a rapid IgM response switching to IgG [23,24] which confers protective immunity for many years [25]. It has been suggested that this long-lasting antibody response is in part due to the presence of viral particles held by follicular dendritic cells in the lymph nodes of cattle, long after the disease has been resolved [26]. Depletion of T cell subsets by monoclonal antibodies showed that the early antibody response to infection is $\mathrm{T}$ cell independent [23].

The aim of the current study was to define the early innate and adaptive immune responses of cattle infected with $\mathrm{O}$ serotype FMDV, after they were held in close contact with cattle infected by intra-dermolingual challenge. Specifically, we determined whether there was generalised immune-suppression during the acute phase of FMDV infection in cattle by monitoring the number of leucocytes in the blood and assaying for inflammatory and anti-inflammatory cytokines and suppression of the $\mathrm{T}$ cell response. We also determined how rapidly FMDVspecific humoral and cell-mediated immune responses developed.

\section{Materials and methods Infection with FMDV}

Male Holstein/Friesian cattle weighing approximately 150 $\mathrm{kg}$ were used for these studies. Two animals were exposed to two separate intra-dermolingually challenged cattle $\left(1 \times 10^{5.7}\right.$ TCID $_{50}$ of cattle-adapted FMDV O UKG $34 / 2001)$ for $24 \mathrm{~h}$. These inoculates formed no part of the subsequent study and only the "naturally" exposed animals will be referred to from here on. This procedure was repeated in three sequential studies and the data presented here are an accumulation of these replicates
$($ replicate one $=$ animal $\mathrm{C} 1$, replicate two $=$ animals $\mathrm{C} 2$ and $\mathrm{C} 3$ and replicate three $=\mathrm{C} 4$ to $\mathrm{C} 6$ ) .

\section{Vaccination}

Five Holstein/Friesian cattle (C7 to $\mathrm{C} 11)$ were vaccinated intramuscularly with $2 \mathrm{~mL}$ of O1Manisa vaccine (O1 Manisa vaccine from the UK FMDV emergency vaccine bank).

\section{Haematology}

Blood samples were collected into anti-coagulant, EDTA, and total leucocyte counts performed on the same day as collection. Each sample was counted in triplicate using a Sysmex haematology analyser (Sysmex F800 Sysmex corporation Kobe Japan).

\section{Virus detection}

Nucleic acid extraction and analysis was performed using quantitative real-time reverse transcription polymerase chain reaction (qRT-PCR) as described previously [27].

\section{Virus-neutralising antibody test}

Serum samples were tested for anti-FMDV neutralising antibodies as described in the Office International des Epizooties Manual of Diagnostic Tests and Vaccines for Terrestrial Animals. Sera with titres greater than or equal to 45 were considered to be positive [28].

\section{Liquid-phase blocking ELISA}

The liquid-phase blocking ELISA was performed as described by Hamblin et al. [29]. Briefly; virus was bound to immunosorbent plates by being trapped with rabbit anti-O1 Manisa antibody. Test samples of bovine sera were mixed with known standards of guinea pig sera and the resultant competition determined by measuring the amount of guinea pig serum bound to the antigen.

\section{Interferon assay}

Type 1 IFN biological activity was measured in serum samples using an $M x /$ chloramphenicol acetyltransferase $(\mathrm{Mx} / \mathrm{CAT})$ promoter-reporter gene assay [30].

\section{IL-10 ELISA}

IL-10 was measured in serum following the method of Kwong et al. [31]. Briefly, ELISA plates were coated with anti-IL-10, cattle sera were applied in duplicate, along with an IL-10 standard series, and detected with biotinylated anti-bovine IL-10. This assay was repeated 3 times.

Vaccination with commercial bovine herpes virus-1 (BHV) vaccine

Approximately one month prior to FMDV challenge, animals $\mathrm{C} 1$ to $\mathrm{C} 6$ were immunised with Tracherine 
(Intervet, NL). Cattle were assayed for proliferative response to $\mathrm{BHV}$ antigen immediately prior to challenge with FMDV. However, the BHV-specific T cell proliferative response to the vaccine was variable; as a consequence, only animals with $\mathrm{T}$ cell proliferative responses consistently higher than $30000 \mathrm{cpm}$ prior to FMDV infection ( $\mathrm{C} 1, \mathrm{C} 4, \mathrm{C} 5$ and $\mathrm{C} 6)$ were included in the analysis of whether FMDV infection significantly affected specific recall responses.

\section{Proliferation assays}

Heparinised blood was diluted with phosphate-buffered saline (PBS) (Invitrogen, Paisley, UK) and centrifuged over Histopaque-1077 (Sigma) at $1328 \mathrm{~g}$. Peripheral blood mononuclear cells (PBMC) were collected from the interface, the red blood cells were lysed in erythrocyte lysis buffer (155 mM ammonium chloride, $0.1 \mathrm{mM}$ EDTA and $10 \mathrm{mM}$ sodium bicarbonate, $\mathrm{pH}$ 7.2) and PBMC were washed three times with cold PBS. PBMC (2 $\times 10^{5}$ per well) in proliferation medium (RPMI 1640 supplemented with 5\% BVDV-free FCS, 1\% non-essential amino acids (Invitrogen) $1 \mathrm{mM}$ sodium pyruvate (VWR, Leicestershire, UK), $10 \mu \mathrm{g} / \mathrm{mL}$ gentamicin and $50 \mu \mathrm{M} 2$ mercaptoethanol) were incubated with a range of antigens; control and test antigens were added to each well. Antigens included; medium alone, pokeweed mitogen $(2.5 \mu \mathrm{g} / \mathrm{mL}$ Sigma), inactivated FMDV antigen, mock infected BHK-21 cell lysate and BHV antigen (heat inactivated prior to use). FMDV antigen was kindly provided by Merial Animal Health, (total antigen concentration was known by the vaccine company but undisclosed). Both FMDV and BHV antigens were previously titrated for use in proliferation assays using PBMC from appropriately vaccinated cattle, with the final concentrations used being 1/1000 for FMDV antigen and 1/100 for $\mathrm{BHV}$. The cultures were incubated for 5 days before $0.037 \mathrm{MBq}\left[{ }^{3} \mathrm{H}\right]$ Thymidine (Amersham, Buckinghamshire, UK) was added to each well. After a further overnight incubation cells were harvested onto filter mats and incorporated radioactivity was measured using a 1450 Microbeta counter (Wallac, Finland).

\section{Statistical analysis}

Linear mixed models were used to investigate the relationship between log10 CPM levels, antigen and time. Model selection proceeded by stepwise deletion of nonsignificant terms (as judged by the Akaike information criterion), starting from a model including antigen, time (as a factor) and an interaction between them; animal was included as a random effect. A linear mixed model was also used to compare IL-10 levels over time, with the model including time (as a factor) as a fixed effect and animal as a random effect.

\section{Results}

Viraemia and neutralising antibody responses after challenge with FMDV

The onset and duration of viraemia after cattle have been challenged with FMDV has been described previously, and the results obtained in this study are consistent with previous reports $[27,32]$. In the six animals studied, viraemia was first detected between 2 and 4 days after the animals were placed in contact with FMDV needle challenged animals. Typical clinical signs were observed in all the cattle from 2 to 4 days post infection (data not shown), and viraemia was resolved in all animals by day 7 (Figure 1a). All animals had seroconverted to FMDV as demonstrated by liquid-phase blocking ELISA (data not shown). All these animals had detectable neutralising antibodies seven days after challenge (Figure 1b) and all were considered to have protective titres $(>45)$ by 14 days after challenge.

\section{Total circulating leucocyte counts during the acute phase of FMDV infection}

Total circulating leucocyte counts did not significantly fluctuate between day -2 prior to challenge and day 8 after challenge (Figure 2). In addition, the mean circulating leucocyte count of the cattle did not deviate above or below the normal physiological range [33].

Whole lysed blood from two of the cattle (C2 and C3) was also examined for any changes in CD4, CD8, WC1, CD21 and NK cell leucocyte populations [7] but these were not found to vary during the course of infection (data not shown), which is in keeping with the results of Juleff et al. [23].

\section{Proliferative response of PBMC to mitogen (PWM) during the acute phase of FMDV infection}

Detailed analysis on the proliferative response to Pokeweed mitogen (PWM) in all six animals (C1 to C6) was carried out (Figure 3) (there were minor variations in sample days due to unavoidable differences in sampling schedules between replicates). Marked proliferation, (greater than $200000 \mathrm{cpm}$ ), of PBMC to PWM was detected at various time-points between day -1 prior to FMDV infection and day 19 after challenge.

\section{Development of FMDV-specific T cell responses during the resolution of acute infection}

FMDV-specific $\mathrm{T}$ cell responses were measured by proliferation of PBMC to virus antigen in animals $\mathrm{C} 1$ to $\mathrm{C6}$ (Figure 3). Although there appears to be a small rise in proliferation to FMDV antigen at day 19 in animals C2 to $\mathrm{C6}$, it was not found to be significant when the data for all animals were exposed to statistical examination. More precisely, there was no significant $(P=0.57)$ 


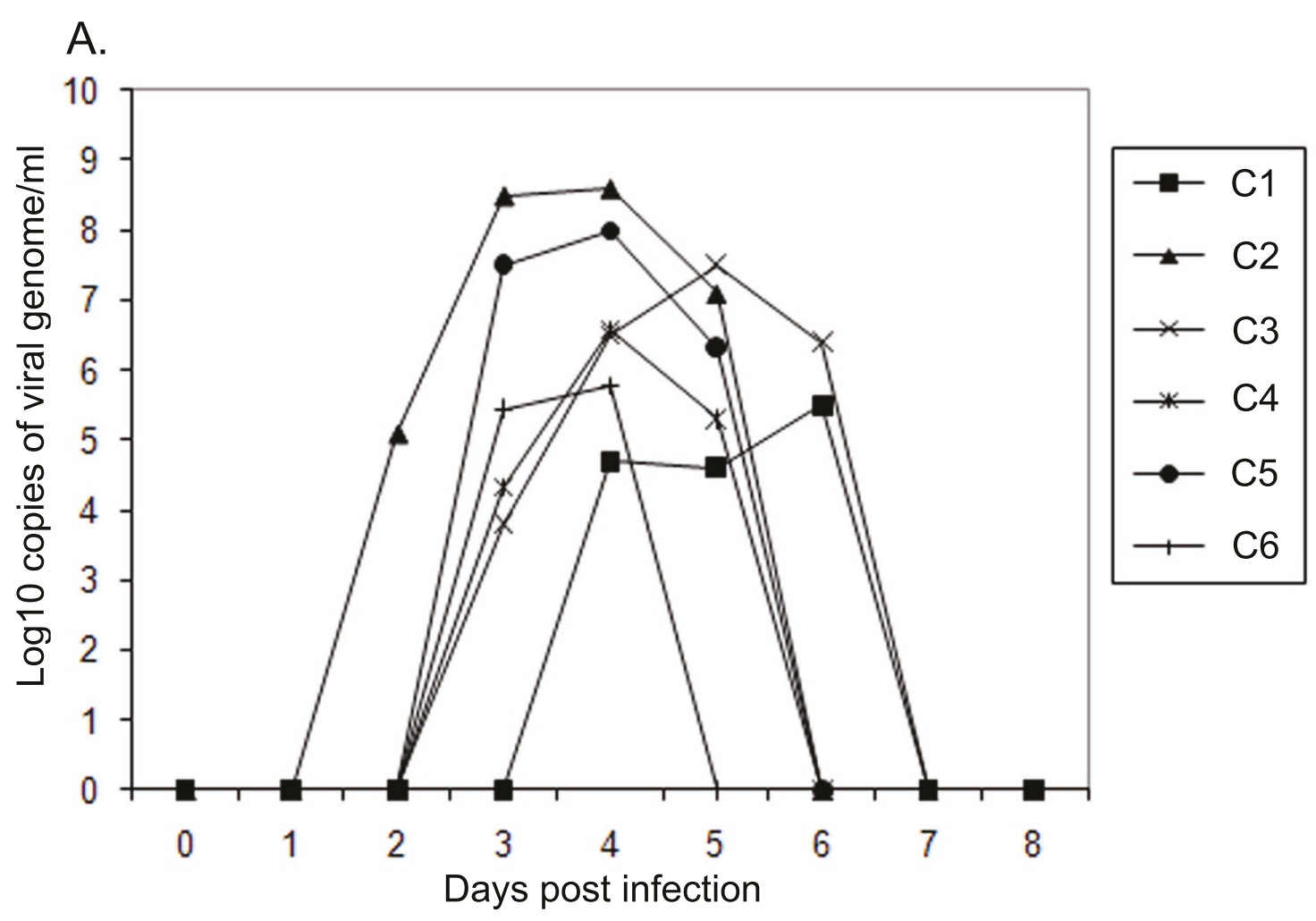

B.
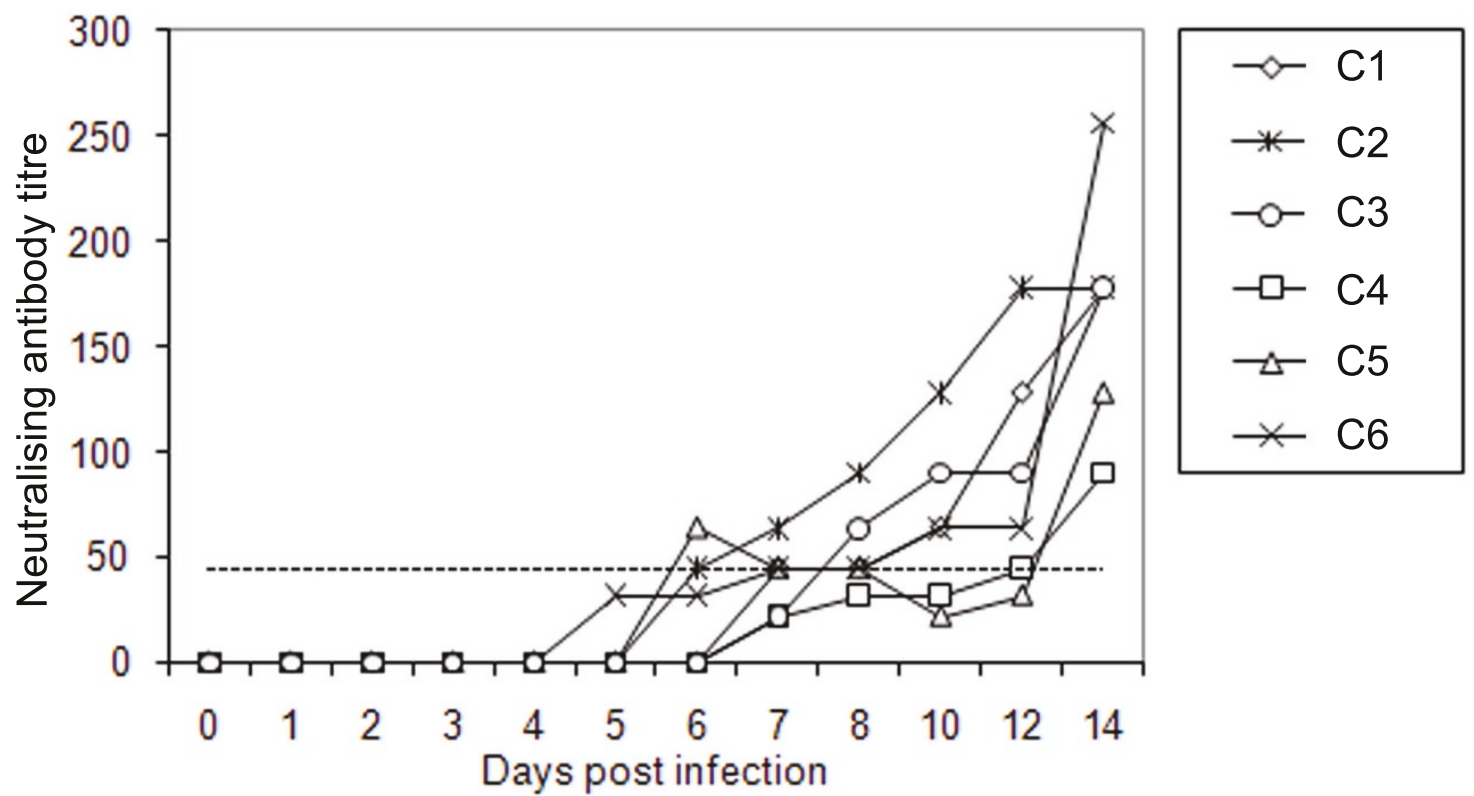

Figure 1 Cattle infected with FMDV were viraemic during acute infection and developed neutralising antibodies. A. Onset and duration of viraemia of all six FMDV challenged cattle used in this study as obtained by quantitative real-time reverse transcription polymerase chain reaction (qRT-PCR). B. Neutralising antibody titre in serum of infected cattle. Sera with titres greater than or equal to 45 were considered to be positive (dotted line). 


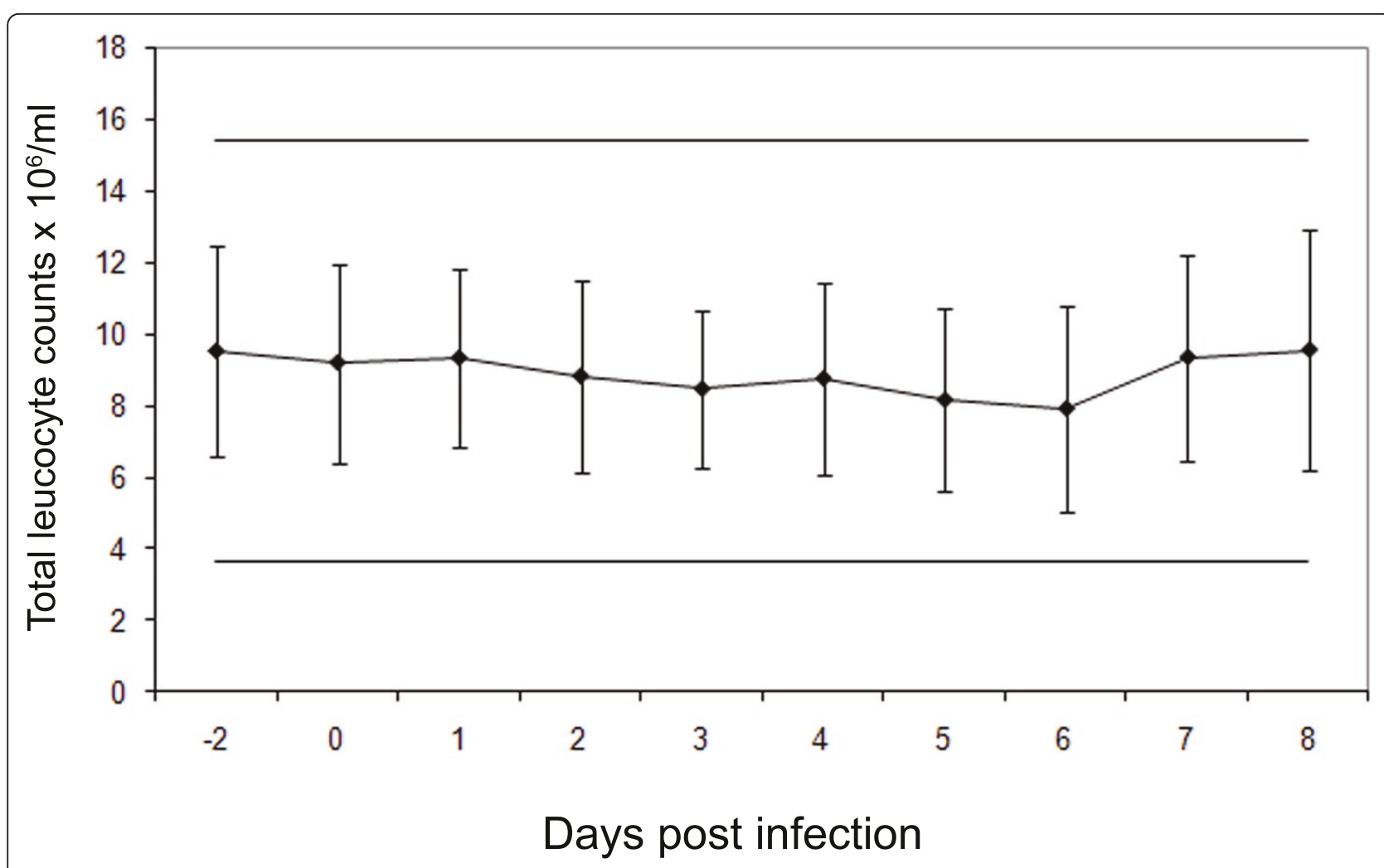

Figure 2 Total circulating leucocyte counts from all six FMDV challenged cattle (C1 to C6) during the acute phase of FMDV infection Blood samples were collected into EDTA, and total leucocyte counts performed on the same day as collection. Counts were performed in triplicate on each sample. $(N=6)$ Lines show $2 X$ STDEV of day 0.

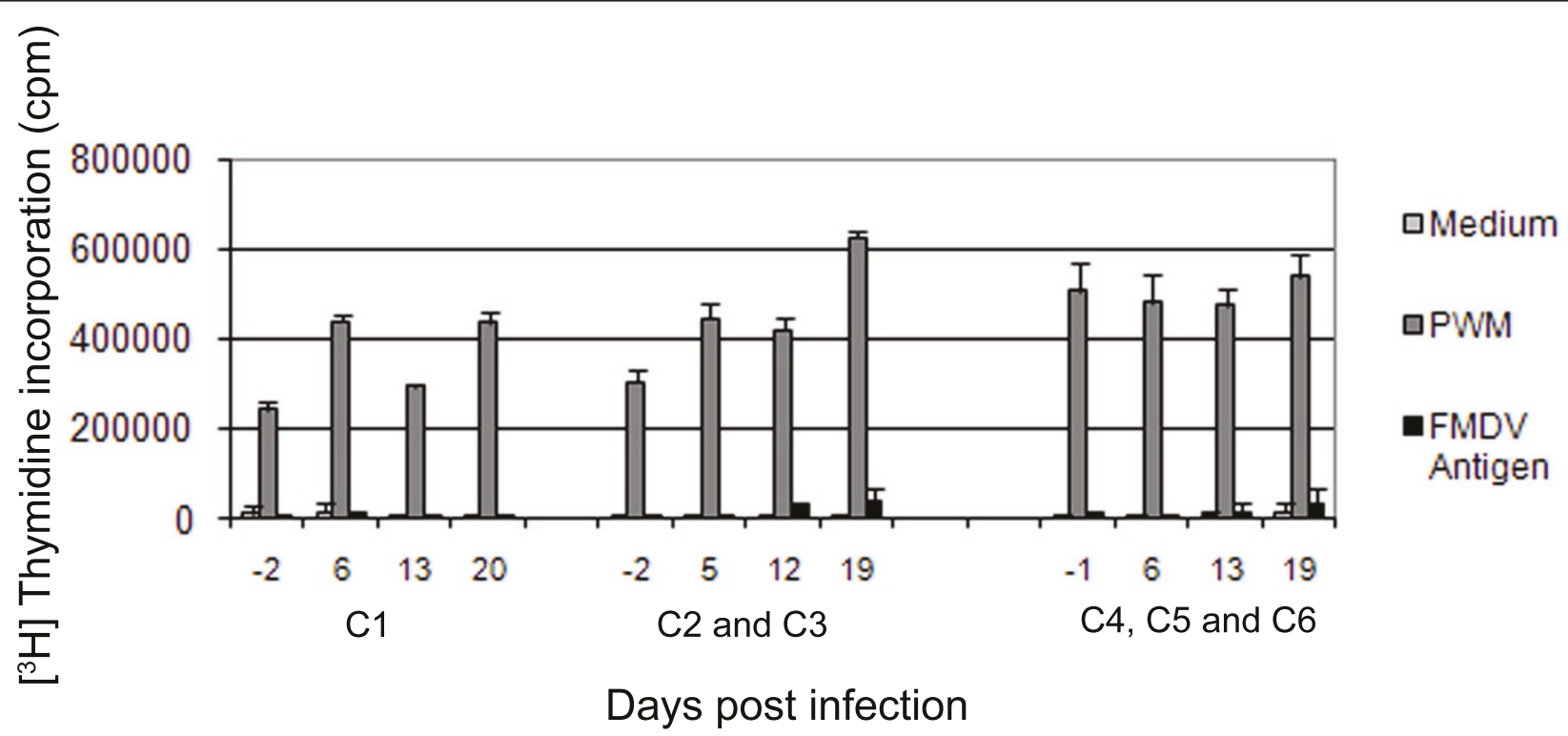

Figure 3 Proliferative response of PBMC to mitogen during the acute phase of FMDV infection. PBMC from infected cattle were assayed for proliferation following in vitro incubation with Pokeweed mitogen and FMDV antigen in triplicate. Data shown is the mean of animals in each replicate (C1, C2 and C3 and C4 to C6) for each time point. Error bars show STDEV of all animals in each group for each time point. 
interaction between time and antigen, and $\log 10 \mathrm{CPM}$ levels did not change significantly $(P=0.31)$ over time for any of the antigens (medium, FMDV or PWM). There was however, a significant $(P<0.001)$ difference in $\log 10$ CPM levels amongst antigens, with levels for PWM being significantly higher than for FMDV or medium (which did not differ significantly $(P=0.08)$ from one another).

Analysis of established specific memory $T$ cell responses during the acute phase of FMDV infection

Vaccination with BHV resulted in variable $\mathrm{T}$ cell responses in individual animals (Figure 4), but $\log 10$ CPM levels were significantly $(P<0.001)$ higher for BHV compared with medium and mock $(\log 10 \mathrm{CPM}$ levels did not differ significantly $(P=0.71)$ between mock and medium). However, for BHV, there was no significant change in $\log 10 \mathrm{CPM}$ levels at any time point post FMDV infection.

\section{Development of FMDV-specific T cell responses after vaccination}

Five cattle ( $\mathrm{C} 7$ to $\mathrm{C} 11)$ were vaccinated with $\mathrm{O} 1 \mathrm{Manisa}$ commercial vaccine and examined for $\mathrm{T}$ cell responses by PBMC proliferation assays (Figure 5). After day 21 animals $\mathrm{C} 8, \mathrm{C} 9$ and $\mathrm{C} 10$ were boosted. An increase in proliferative response was seen in these animals with counts per minute rising to approximately 300 000, 400000 and 500000 cpm respectively. The $\mathrm{T}$ cell response to FMDV antigen following vaccination was variable in individual cattle, but by inspection, when a response was seen, it was always earlier and of greater magnitude than after infection (it is not appropriate to perform statistical analyses between the studies in Figures 3 and 5).

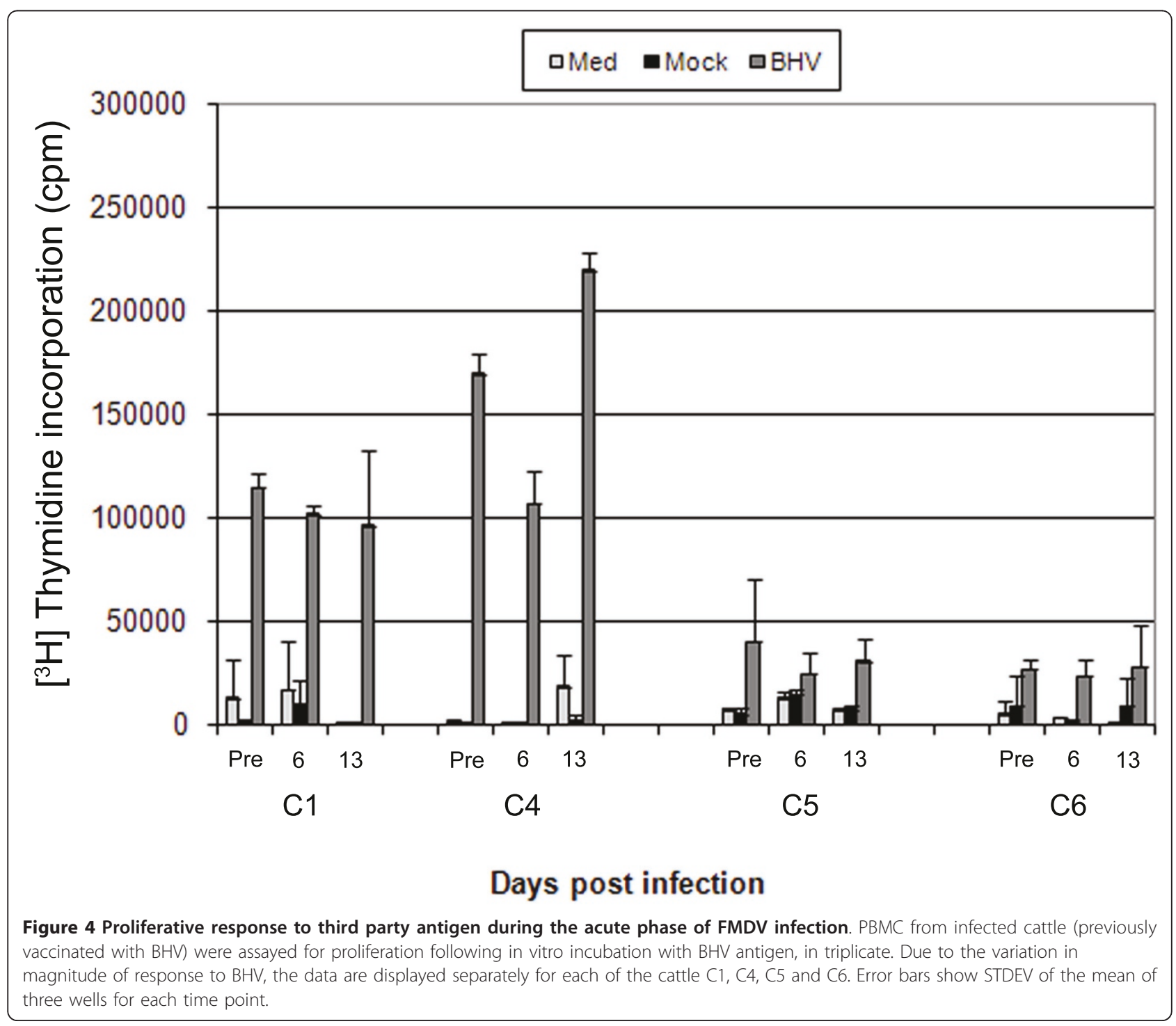




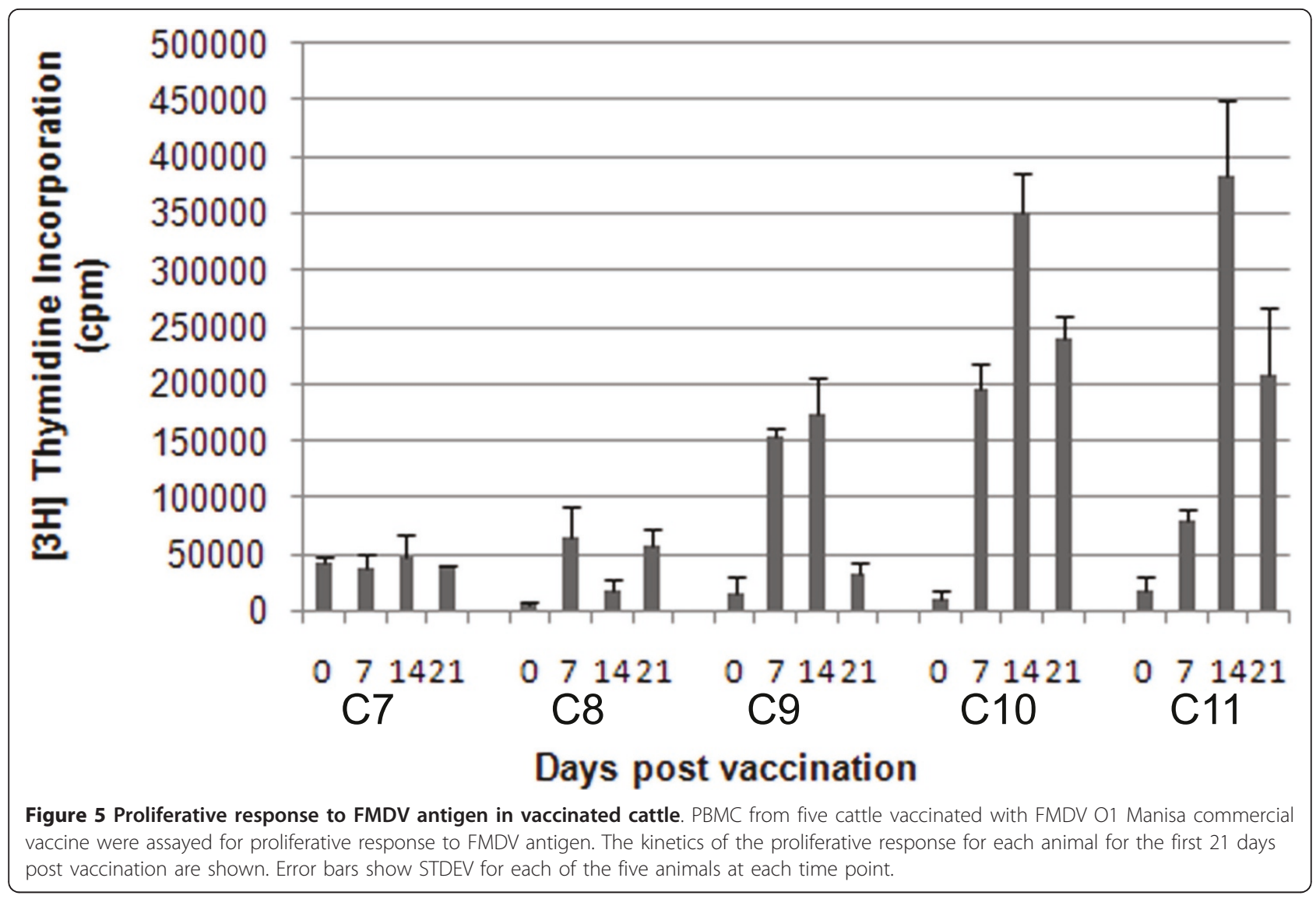

\section{Detection of circulating type 1 IFN during the acute phase of FMDV infection}

Type 1 IFN was assayed from the sera of six infected cattle (Figure 6). Production of type 1 IFN following infection with FMDV was variable, with the peak values varying between 1 and 14 international units/mL (IU/mL).

\section{Detection of circulating IL-10 during the acute phase of FMDV infection}

Six cattle (C1 to C6), were assayed for circulating IL-10 before, during, and after the acute phase of FMDV infection (Day -2 through to day 8, Figure 7). Low, but statistically significant compared to pre-challenge $(P<0.03)$, levels of IL-10 were detected in all animals, rising over time, reaching a peak on average of $1.35 \mathrm{IU} / \mathrm{mL}$ between day 3 and 4, after which they declined.

\section{Discussion}

Early studies by Cunliffe et al. [25] established the long duration of immunity following infection with FMDV in cattle. In contrast, current commercial vaccination protocols require regular re-inoculation to maintain immunity. Analysing the differences in the immune response in the natural host during these two processes may lead to the design of more effective vaccines.
By exposing six cattle to FMDV this study aimed to; investigate whether a generalised suppressive state is induced, compare early $\mathrm{T}$ cell responses to those of vaccinates, and examine the expression of key immune-modulatory cytokines.

After natural exposure to FMDV, viraemia is typically detectable within 2 to 3 days followed by clinical signs [27]. Production of high titres of neutralising antibodies can be detected as early as six days following natural infection, by a process shown previously to be $\mathrm{T}$ cell independent in cattle [23]. These previous observations were confirmed in all of the cattle used in this study. Compared to the rapid production of antibody, significant FMDV-specific T cell responses (assayed by proliferation of PBMC) were not observed following natural infection. These data are supported by other cattle studies, with no FMDV-specific $\mathrm{T}$ cell response detectable up to 32 days post exposure in some cases (M. Windsor unpublished data). We also investigated whether there was any loss of mitogen or specific antigen induced $\mathrm{T}$ cell proliferative responses during the course of acute infection. Abrogation of proliferation of PBMC to mitogen in pigs occurs between 2 and 8 days but most noticeably at day 5 after needle challenge [7]. Following natural challenge, peak viraemia in cattle occurs at least two days later than needle challenge [34], which is 


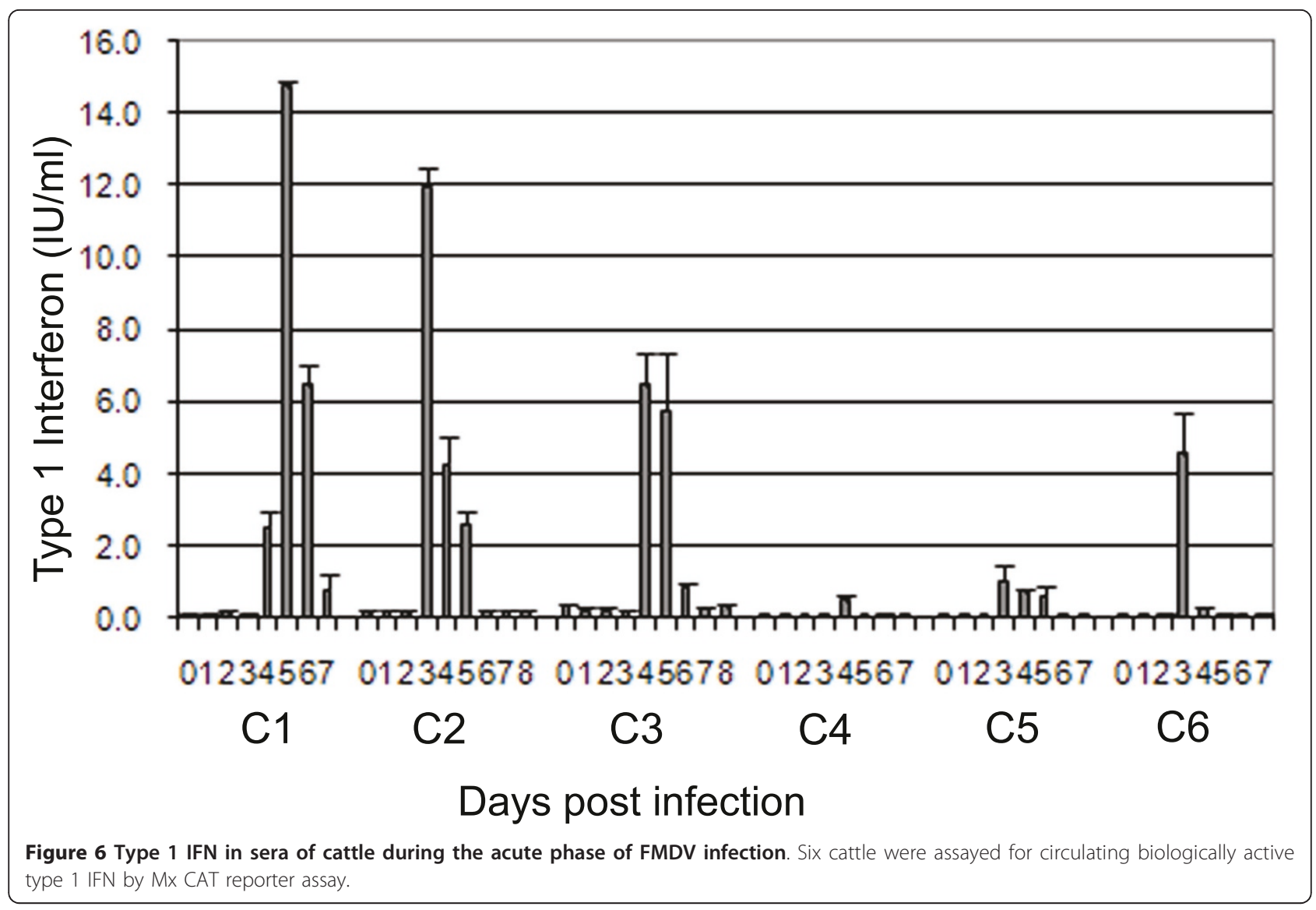

consistent with the pattern of viraemia in our study. We did not observe any loss of mitogen or specific antigen induced $\mathrm{T}$ cell proliferative responses on day 6 post-infection. Even though a specific $\mathrm{T}$ cell response to FMDV could not be detected during the acute stages of infection, the $\mathrm{T}$ cell proliferative responses to mitogen and a third party antigen (BHV) were unaffected.

In a previous study using bovine dendritic cells (DC), Robinson et al. [35] showed that, in vitro, DC infection was enhanced by the formation of FMDV immune complexes. These data suggest that as FMDV rapidly loses its ability to infect susceptible cells due to increasing neutralising antibody titres, it gains the capacity to infect immune cells via CD32 (Fc $\gamma \mathrm{R})$. These findings by Robinson et al. suggest that infection and killing of DC by immune-complexed FMDV may be responsible in part for the delayed FMDV-specific $\mathrm{T}$ cell proliferative response [35]. Clearly, it is not the ability of the $\mathrm{T}$ cells to respond that is affected, as evidenced by the maintenance of established $\mathrm{T}$ cell responses to mitogen and third party antigen.

The FMDV-specific $\mathrm{T}$ cell proliferative response in the five vaccinates was variable. Where an effective response to antigen was seen, it was of a high magnitude and detectable from seven days post vaccination. It should be noted that although the initial response was low in some cattle, they all subsequently went on to develop a similar magnitude of $\mathrm{T}$ cell response following a booster vaccination, showing that there was no underlying impairment of the response in these animals.

Transient lymphopenia has been observed in swine following infection with FMDV which correlated with the virulence of the isolate used [7]. In cattle, we were unable to detect any evidence of lymphopenia, with the numbers of leucocytes remaining constant and within physiological ranges during the period of viraemia and clinical FMD. Leukocyte subsets were also examined in whole lysed blood in two of the animals and no changes were observed, confirming our previous observations [23]. This contrasts studies in pigs, where a significant loss of circulating $\mathrm{CD}^{+}$and $\mathrm{CD}^{+} \mathrm{T}$ cells was observed [7].

Studies in pigs have found high levels of type 1 IFN following experimental infection with several FMDV isolates $[10,36]$, which correlates with immune suppression. Due to the different methods of quantification used in these studies, it is problematic to compare the levels of IFN produced. In cattle we have measured the specific 


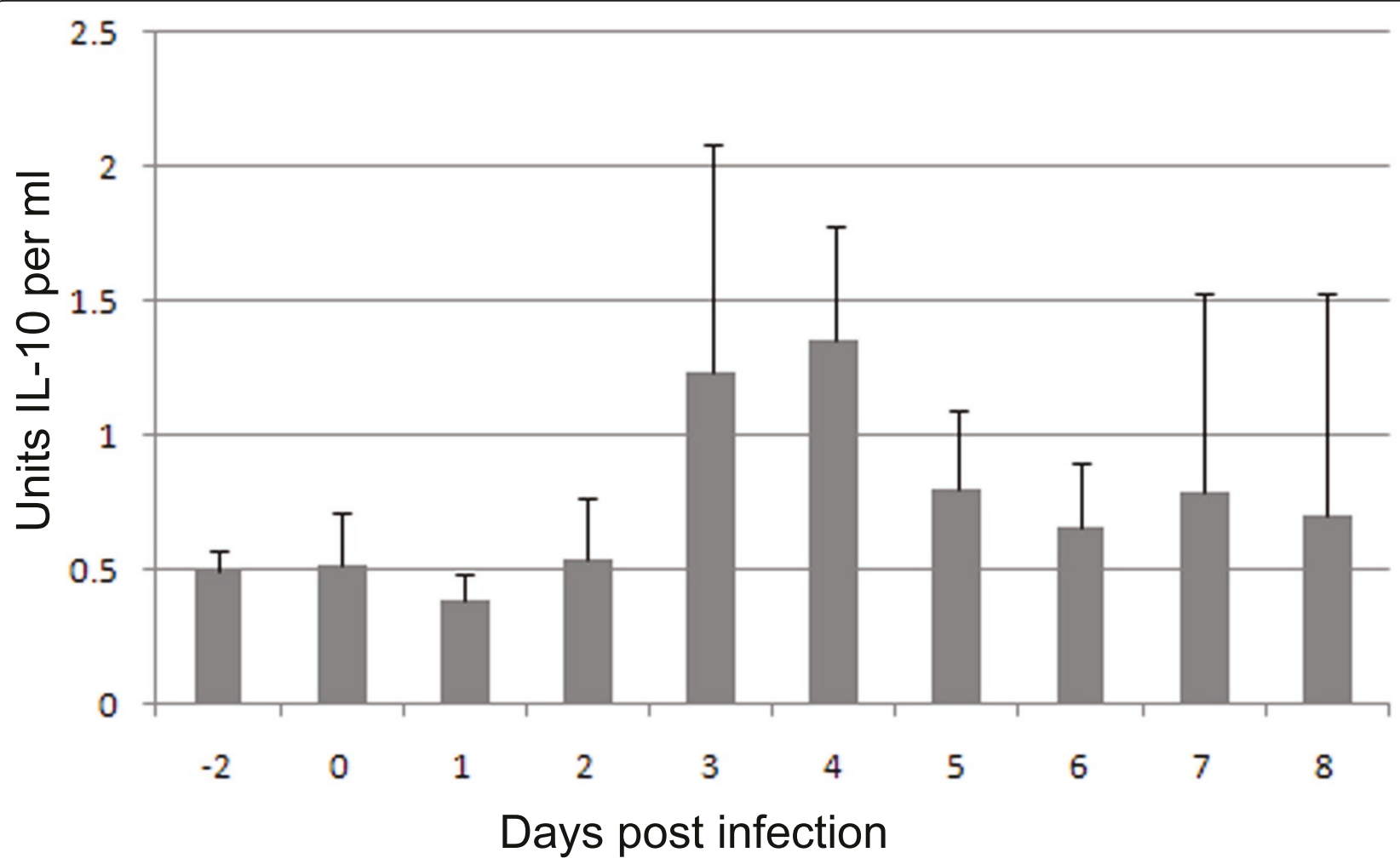

Figure 7 IL-10 in sera of cattle during the acute phase of FMDV infection. Six cattle were assayed for circulating IL-10 by ELISA from day -2 to day 8 post infection. Data shown is the mean of all six animals (C1 to C6). Error bars show STDEV of the mean.

activity of type 1 IFN (in international units), whereas total circulating type 1 IFN protein was measured in pig serum. However, this IFN is not necessarily biologically active. Several sources, including manufacturers' data sheets, give type 1 IFN specific activity (cross species) at between 1 and $3 \times 10^{8} \mathrm{IU} / \mathrm{mg}$ of total IFN. Using this calculation we can speculatively compare type 1 IFN in the sera of pigs and cattle during FMDV infection, and postulate that pigs do indeed produce more IFN than the cattle in this study. The most compatible study in pigs was performed by Nfon et al., who used O1Campos challenge [10]. At least 9 fold more type 1 IFN was produced in pigs compared to our results in cattle. In pigs, IFN clearly has an important role to play in the resolution of infection, as the administration of type 1 IFN in a viral vector protects against subsequent challenge with FMDV [37].

Our study implies that cattle produce very little type 1 IFN in comparison to pigs, which is in keeping with previous studies [38], yet cattle still resolve the disease effectively. Depletion of $\mathrm{CD} 4^{+}$cells in cattle during infection further reduces circulating type I IFN, but infection is still resolved [23], indicating that the presence of type 1 IFN in the circulation may not have any bearing on the resolution of disease. The IFN detected in the circulation during FMDV infection in cattle is thought to be produced by $\mathrm{CD} 4^{+}$PDCs interacting with immune-complexed virus [39]. The PDCs found in cattle secondary lymphoid tissue are capable of producing large amounts of IFN in vitro [39]. It is possible therefore, that IFN does play a local role at the sites of infection such as lesions, or in the lymph nodes, and that the IFN found in the circulation is derived from these high concentration sources. Summerfield et al. and Nfon et al. found large numbers of circulating PDCs in pigs $[10,40]$ in comparison to the low numbers detectable in cattle. Nfon also found that these PDCs were functionally impaired during the latter stages of infection with FMDV.

Low levels of IL-10, corresponding with the peak of clinical signs, were found in the serum of the cattle studied. Whilst IL-10 does appear to play a role in immune suppression in pigs during infection with FMDV [8], it is most commonly associated with the maintenance of chronic infections such as Hepatitis $\mathrm{C}$ in humans $[41,42]$ and Mycobacterium Bovis in cattle [43]. Studies in mice have shown that FMDV infected DC can stimulate splenic $\mathrm{CD} 9^{+} \mathrm{B}$ cells to produce $\mathrm{T}$-independent neutralising IgM antibodies, via an IL-10 dependent process [44]. We propose that the absence of leucopenia 
and immunosuppression in cattle, during acute FMDV infection, is associated with the low levels of type 1 IFN and IL-10. These differences in cytokine profile between pigs and cattle may also explain why, in general, more severe clinical signs are seen in pigs infected with FMDV [45].

\section{Acknowledgements}

The authors would like to thank Paul Barnett, Sarah Cox, Luke Fitzpatrick, Colin Randall and Luca Colmari for assistance with animal work and collection of samples and the BBSRC for funding.

\section{Author details}

${ }^{1}$ Pirbright Laboratory, Institute for Animal Health, Ash Road, Woking, Surrey, GU24 ONF, UK. ${ }^{2}$ Compton laboratory, Institute for Animal Health, Compton, Berkshire, RG20 7NN, UK

\section{Authors' contributions}

MW carried out the circulating leucocyte counts, proliferation assays of infected cattle, IL10 ELISAs, FACS analysis, analysis and interpretation of data and wrote the manuscript. BVC carried out proliferation assays of vaccinated cattle. BB conducted in vivo experiments, determined viraemia and contributed to experimental design. DG conducted in vivo experiments determined viraemia and carried out competition ELISAs. ER carried out Interferon assays. PH carried out VNT assays. SG carried out statistical analysis. NJ conducted in vivo experiments, carried out IFN assays, coordinated experimental design, analysis and interpretation of data and assisted with manuscript. BC initiated experimental design, analysis and interpretation of data and assisted with manuscript. All authors have read and approved the final manuscript.

\section{Authors' Information}

$\mathrm{BC}$ is a Jenner investigator and $\mathrm{NJ}$ is a Welcome Trust intermediate clinical fellow.

\section{Competing interests}

The authors declare that they have no competing interests.

Received: 17 May 2011 Accepted: 20 October 2011

Published: 20 October 2011

\section{References}

1. Ferguson NM, Donnelly CA, Anderson RM: The foot-and-mouth epidemic in Great Britain: pattern of spread and impact of interventions. Science 2001, 292:1155-1160

2. Paton DJ, King DP, Knowles NJ, Hammond J: Recent spread of foot-andmouth disease in the Far East. Vet Rec 2010, 166:569-570.

3. Golde WT, de Los Santos T, Robinson L, Grubman MJ, Sevilla N, Summerfield A, Charleston B: Evidence of activation and suppression during the early immune response to foot-and-mouth disease virus. Transbound Emerg Dis 2011, 58:283-290.

4. Arzt J, Pacheco JM, Rodriguez LL: The early pathogenesis of foot-andmouth disease in cattle after aerosol inoculation: identification of the nasopharynx as the primary site of infection. Vet Pathol 2010, 47:1048-1063.

5. Zhang Z, Alexandersen S: Quantitative analysis of foot-and-mouth disease virus RNA loads in bovine tissues: implications for the site of viral persistence. J Gen Virol 2004, 85:2567-2575.

6. Barnett PV, Cox SJ, Aggarwal N, Gerber H, McCullough KC: Further studies on the early protective responses of pigs following immunisation with high potency foot and mouth disease vaccine. Vaccine 2002, 20:3197-3208.

7. Bautista EM, Ferman GS, Golde WT: Induction of lymphopenia and inhibition of T cell function during acute infection of swine with foot and mouth disease virus (FMDV). Vet Immunol Immunopathol 2003, 92:61-73.

8. Diaz-San Segundo F, Rodriguez-Calvo T, de Avila A, Sevilla N: Immunosuppression during acute infection with foot-and-mouth disease virus in swine is mediated by IL-10. PLoS One 2009, 4:e5659.
9. Golde WT, Nfon CK, Toka FN: Immune evasion during foot-and-mouth disease virus infection of swine. Immunol Rev 2008, 225:85-95.

10. Nfon CK, Toka FN, Kenney M, Pacheco JM, Golde WT: Loss of plasmacytoid dendritic cell function coincides with lymphopenia and viremia during foot-and-mouth disease virus infection. Viral Immunol 2010, 23:29-41.

11. Theofilopoulos AN, Baccala R, Beutler B, Kono DH: Type I interferons (alpha/beta) in immunity and autoimmunity. Annu Rev Immunol 2005, 23:307-336.

12. Chinsangaram J, Koster M, Grubman MJ: Inhibition of L-deleted foot-andmouth disease virus replication by alpha/beta interferon involves double-stranded RNA-dependent protein kinase. J Virol 2001 75:5498-5503.

13. Dias CC, Moraes MP, Segundo FD, de Los Santos T, Grubman MJ: Porcine type I interferon rapidly protects swine against challenge with multiple serotypes of foot-and-mouth disease virus. J Interferon Cytokine Res 2010, 31:227-236.

14. Diaz-San Segundo F, Salquero FJ, de Avila A, de Marco MM, SanchezMartin MA, Sevilla N: Selective lymphocyte depletion during the early stage of the immune response to foot-and-mouth disease virus infection in swine. J Virol 2006, 80:2369-2379.

15. Maddur MS, Gajendragad MR, Gopalakrishna S, Singh N: Comparative study of experimental Foot-and-Mouth Disease in cattle (Bos indicus) and buffaloes (Bubalis bubalus). Vet Res Commun 2008, 32:481-489.

16. Pestka S, Krause CD, Sarkar D, Walter MR, Shi Y, Fisher PB: Interleukin-10 and related cytokines and receptors. Annu Rev Immunol 2004, 22:929-979.

17. Toka FN, Nfon C, Dawson H, Golde WT: Natural killer cell dysfunction during acute infection with foot-and-mouth disease virus. Clin Vaccine Immunol 2009, 16:1738-1749.

18. Childerstone AJ, Cedillo-Baron L, Foster-Cuevas M, Parkhouse RME: Demonstration of bovine CD8(+) T-cell responses to foot and mouth disease virus. J Gen Virol 1999, 80:663-669.

19. Guzman E, Taylor G, Charleston B, Skinner MA, Ellis SA: An MHC-restricted CD8+ T-cell response is induced in cattle by foot-and-mouth disease virus (FMDV) infection and also following vaccination with inactivated FMDV. J Gen Virol 2008, 89:667-675.

20. Guzman E, Taylor G, Charleston B, Ellis SA: Induction of a cross-reactive CD8(+) T cell response following foot-and-mouth disease virus vaccination. J Virol 2010, 84:12375-12384.

21. van Lierop MJ, van Maanen $K$, Meloen $R H$, Rutten VP, de Jong MA, Hensen EJ: Proliferative lymphocyte responses to foot-and-mouth disease virus and three FMDV peptides after vaccination or immunization with these peptides in cattle. Immunology 1992, 75:406-413.

22. Garcia-Valcarcel M, Doel T, Collen T, Ryan M, Parkhouse RM: Recognition of foot-and-mouth disease virus and its capsid protein VP1 by bovine peripheral T lymphocytes. J Gen Virol 1996, 77:727-735.

23. Juleff $N$, Windsor $M$, Lefevre EA, Gubbins $S$, Hamblin P, Reid E, McLaughlin K, Beverley PC, Morrison IW, Charleston B: Foot-and-mouth disease virus can induce a specific and rapid CD4+ T-cell-independent neutralizing and isotype class-switched antibody response in naive cattle. J Virol 2009, 83:3626-3636.

24. Salt JS, Mulcahy G, Kitching RP: Isotype-specific antibody responses to foot-and-mouth disease virus in sera and secretions of "carrier" and "non-carrier" cattle. Epidemiol Infect 1996, 117:349-360.

25. Cunliffe HR: Observations on the duration of immunity in cattle after experimental infection with foot-and-mouth disease virus. Cornell Vet 1964, 54:501-510.

26. Juleff N, Windsor M, Reid E, Seago J, Zhang Z, Monaghan P, Morrison IW, Charleston B: Foot-and-mouth disease virus persists in the light zone of germinal centres. PLoS One 2008, 3:e3434.

27. Charleston B, Bankowski BM, Gubbins S, Chase-Topping ME, Schley D, Howey R, Barnett PV, Gibson D, Juleff ND, Woolhouse ME: Relationship between clinical signs and transmission of an infectious disease and the implications for control. Science 2011, 332:726-729.

28. Epizooties O.I.d: Manual of diagnostic tests and vaccines for terrestrial animals 2004

29. Hamblin C, Barnett IT, Hedger RS: A new enzyme-linked immunosorbent assay (ELISA) for the detection of antibodies against foot-and-mouth disease virus. I. Development and method of ELISA. J Immunol Methods 1986, 93:115-121. 
30. Fray MD, Mann GE, Charleston B: Validation of an Mx/CAT reporter gene assay for the quantification of bovine type-I interferon. $J$ Immunol Methods 2001, 249:235-244.

31. Kwong LS, Hope JC, Thom ML, Sopp P, Duggan S, Bembridge GP, Howard CJ: Development of an ELISA for bovine IL-10. Vet Immunol Immunopathol 2002, 85:213-223.

32. Alexandersen S, Zhang Z, Donaldson Al, Garland AJM: The pathogenesis and diagnosis of foot-and-mouth disease. J Comp Pathol 2003, 129:1-36.

33. Reece WO: Functional anatomy and physiology of domestic animals Lippincott Williams and Wilkins; 2005.

34. Pacheco JM, Arzt J, Rodriguez LL: Early events in the pathogenesis of foot-and-mouth disease in cattle after controlled aerosol exposure. Vet J 2010, 183:46-53.

35. Robinson L, Windsor M, McLaughlin K, Hope J, Jackson T, Charleston B: Foot-and-mouth disease virus exhibits an altered tropism in the presence of specific immunoglobulins, enabling productive infection and killing of dendritic cells. J Virol 2011, 85:2212-2223.

36. Nfon CK, Ferman GS, Toka FN, Gregg DA, Golde WT: Interferon-alpha production by swine dendritic cells is inhibited during acute infection with foot-and-mouth disease virus. Viral Immunol 2008, 21:68-77.

37. Dias CC, Moraes MP, Segundo FD, de los Santos T, Grubman MJ: Porcine type I interferon rapidly protects swine against challenge with multiple serotypes of foot-and-mouth disease virus. J Interferon Cytokine Res 2011, 31:227-236.

38. Stenfeldt C, Heegaard PM, Stockmarr A, Tjornehoj K, Belsham GJ: Analysis of the acute phase responses of Serum Amyloid A, Haptoglobin and Type 1 Interferon in cattle experimentally infected with foot-and-mouth disease virus serotype O. Vet Res 2011, 42:66.

39. Reid E, Juleff N, Gubbins S, Prentice H, Seago J, Charleston B: Bovine plasmacytoid dendritic cells are the major source of type-1 interferon in response to foot-and-mouth disease virus in vitro and in vivo. J Virol 2011, 85:4297-4308.

40. Summerfield A, Guzylack-Piriou L, Schaub A, Carrasco CP, Tache V, Charley B, McCullough KC: Porcine peripheral blood dendritic cells and natural interferon-producing cells. Immunology 2003, 110:440-449.

41. Flynn JK, Dore GJ, Hellard M, Yeung B, Rawlinson WD, White PA, Kaldor JM, Lloyd AR, Ffrench RA: Early IL-10 predominant responses are associated with progression to chronic hepatitis $C$ virus infection in injecting drug users. J Viral Hepat 2011, 18:549-561.

42. Kaplan DE, Ikeda F, Li Y, Nakamoto N, Ganesan S, Valiga ME, Nunes FA, Rajender Reddy K, Chang KM: Peripheral virus-specific T-cell interleukin-10 responses develop early in acute hepatitis $C$ infection and become dominant in chronic hepatitis. J Hepatol 2008, 48:903-913.

43. Witchell J, Maddipatla SV, Wangoo A, Vordermeier M, Goyal M: Time dependent expression of cytokines in Mycobacterium bovis infected cattle lymph nodes. Vet Immunol Immunopathol 2010, 138:79-84.

44. Ostrowski M, Vermeulen M, Zabal O, Zamorano PI, Sadir AM, Geffner JR, Lopez OJ: The early protective thymus-independent antibody response to foot-and-mouth disease virus is mediated by splenic CD9+ B lymphocytes. J Virol 2007, 81:9357-9367.

45. Alexandersen S, Quan M, Murphy C, Knight J, Zhang Z: Studies of quantitative parameters of virus excretion and transmission in pigs and cattle experimentally infected with foot-and-mouth disease virus. $J$ Comp Pathol 2003, 129:268-282.

doi:10.1186/1297-9716-42-108

Cite this article as: Windsor et al:: Cattle remain immunocompetent during the acute phase of foot-and-mouth disease virus infection. Veterinary Research 2011 42:108.

\section{Submit your next manuscript to BioMed Central and take full advantage of:}

- Convenient online submission

- Thorough peer review

- No space constraints or color figure charges

- Immediate publication on acceptance

- Inclusion in PubMed, CAS, Scopus and Google Scholar

- Research which is freely available for redistribution

Submit your manuscript at www.biomedcentral.com/submit
Biomed Central 